\title{
Auditory Aesthetics and Literary Re-mappings: Trans-medial Forays into Joyce's Ulysses and Beckett's Ping
}

\author{
Ronit Ghosh \\ Aalborg University, Denmark. Email: gronit79@gmail.com. ORCID: oooo-ooo2-8668-1286 \\ Received May 15, 2017; Revised July 21, 2017; Accepted July 25, 2017; Published August 10, 2017.
}

\begin{abstract}
In the present era binaries like poesis/techne or art/non-art are becoming increasingly tenuous with the emergence of New Media art cultures, where technology becomes an integral part of artworks. A spurt of commentaries regarding how New Media has redefined the cognitive, perceptual and artistic limits of what is traditionally regarded as art has resulted. However, there is a dearth of literature on how the conceptual vocabulary of contemporary or traditional art/literary practice has seeped into the precincts of the New Media art world. This, unfortunately, accounts for the current disconnect between contemporary art (which is conceived as conceptual art that is self-reflexive and meta-critical in character) and New Media art discourse (whose distinguishing feature is its tryst with technological implements). In an effort to bridge the conversational lacuna between the literary and the new media art disciplines, this paper indicates formal/structural tendencies in James Joyces's novel Ulysses and Samuel Beckett's short story Ping that evince receptive/interpretive tactics which significantly anticipate trends in Media art of the current times.
\end{abstract}

Keywords: New Media art, perception, Beckett, Joyce, transmedial

\section{Introduction}

Sara Danius, in Senses of Modernism: Technology, Perception and Aesthetics explores how new technological innovations result in the dissociation of human perceptual components, which in turn creates new registers of perception and a reappraisal of experienced reality. The ever-closing relationship between what Danius calls "the habits of the sensorium and the technologies of perception" (Danius,2002, p. 23) marks a transition from perception as a means to attain "discursive knowledge" about reality to perception as an "aesthetic end in itself"(an apperception of sorts). The epistemological and even ontological transformations that accompany the emergence of novel forms of media technology introduce a new scale in human affairs and unique patterns of organization, interaction and relationality.

In the present era binaries like poesis/techne or art/non-art are becoming increasingly tenuous with the emergence of New Media digital art cultures, where technology becomes an integral part of artworks. A spurt of commentaries regarding how New Media has redefined the cognitive, perceptual and artistic limits of what is traditionally regarded as art exists. However, there is a dearth of literature on how the conceptual vocabulary of contemporary or traditional art practice has seeped into the precincts of the New Media art world. This, unfortunately, accounts for the current disconnect between contemporary art (which is conceived as conceptual art that is self-reflexive and meta-critical in character) and New Media art discourse (whose distinguishing feature is its tryst with technological implements).

(c) AesthetixMS 2016. This Open Access article is published under a Creative Commons Attribution Non-Commercial 4.0 International License (http://creativecommons.org/licenses/by-nc/4.o/), which permits non-commercial re-use, distribution, and reproduction in any medium, provided the original work is properly cited. For citation use the DOI. For commercial re-use, please contact editor@rupkatha.com. 
The synesthetic experience premised on the trans-medial technological resources associated with New Media art installations can forge a crucial but hitherto marginalized link between the two spheres of art. I hold that it is not only the onslaught of new forms of media (in their material aspect) on traditional media like print but also the technical vocabulary associated with a certain art medium which, when applied to the conceptualization of other art media, reconfigures their limits and possibilities in significant ways. This cross-fertilization of an aesthetic medium by formal/technical vocabulary from other aesthetic media could be regarded as a 'conceptual metaphor' (to use a term coined by Lakoff and Johnson) ${ }^{1}$ which impregnates the original art medium (on which resources of another medium are superimposed) with newer matrices of operation.

For example, it is interesting to note how various imaginaries/metaphors through which music as a medium has been conceived across the ages has significantly governed the character of the music emerging from that particular time-space location. Conceptualizing musical art along the trajectory of architectural three-dimensionality witnessed an unmatched development in the art of complex counterpoint and harmony in Baroque music which carves out a spatial register where the various independent musical voices are premised on strict proportionality. These metaphors, one could suggest, alter the range of anticipation associated with a work of art, thereby preparing the ground for conceptualizing the same artwork across radically different coordinates. This transition in conception would then create newer levels of articulation of experience and complicate the question of 'affect' associated with art in interesting ways. Since the critical assumptions associated with a certain art form/medium would undergo modification when the vocabulary of newer art/media forms seep into its formal and cognitive domains, there is a consequent change in the affective potential and possibilities of that art/media form.

These ruminations regarding art/media forms and their complex relation to perception, affect or cognition significantly inform radical modernist works like James Joyce's Ulysses or Samuel Beckett's short story Ping. They have been studied as monuments of ground-breaking trans-medial experimentation. However, this paper investigates these works in the light of unique perceptual, cognitive and artistic possibilities inaugurated by them which, I argue, anticipate the aesthetics associated with New Media art works.

\section{2. 'Bloomusalem Liberated' : Rejecting 'Form' and Introducing 'Fragment' to the Study of Joyce's Ulysses}

I propose that Joyce, in works like Ulysses, uniquely radicalizes and re-appropriates the written word/'sign'. He affects a style of writing which, by foregrounding and isolating words, sounds and syllables in a sentence imbues them with a semiotic potential. There is a productive tension between the sign as a self-referential, isolated monument staging its materiality and the sign as a site of multi-valent semantic contestation. Besides, this severing and rupturing of the sign recalibrates it along new modalities of experience as against 'interpretation'. Put simply, the processual registers through which interpretation takes place are unravelled, thus arresting the written letter(s)/word in the process of signification.

The interplay of the 'semiotic' and the 'semantic' registers opens up a new mode of experiencing the literary text sensorily as well as discursively. This, I contend, is a unique feature of the literary/linguistic medium. The linguistic sign exists in the economy of the Joycean text as part of innumerable "discursive terrains" and "organizational grids", as Udaya Kumar puts it.

Kumar posits that, "the sign bears on its surface the traces of diverse worlds. The reference to the 
subjective origin of the sign by using an inventory attached to a particular character continues.

But along with it, there emerge the inventories of episodes, of allusions, and of internal repetitions. Thus the origin, the grounding of the sign, gets ruptured and fragmented. The sign seems more to be the product of its circulation, of the history of its alliances." (Kumar, 1991, p. 95)

An instance from the text would help illuminate the contention. In the Circe episode, Joyce puts the traditional Irish ballad Doran's Ass to good use. While rebuking Leopold Bloom, Madame Bello says, "I'll teach you to behave like a jinkleman! ... Aha! By the ass of the Dorans you'll find I'm a martinet" (Joyce,1922, p. 912) According to Gifford and Seidman, "Doran's Ass" is an Irish ballad about one Paddy Doyle who, drunk one night, mistakes Doran's jackass for his sweetheart, Biddy Tool, and copulates with the ass. Suddenly realizing what he has just done, Paddy then rushes back to Biddy. The text of the ballad runs as follows: "He told her the story mighty civil While she prepared a whiskey glass: How he hugged and smugged the hairy divil "Go long," says she, "'twas Doran's ass!" "I know it was, my Biddy darling." They both got married the very next day, But he never got back his old straw-hat That the jackass ate up on the way". (as cited in Nestrovski.1994, p. 16)

As Arthur Nestrovski(1994) points out in his article, Joyce's character Biddy Doran owes its source to this ballad and that Joyce has mingled the girl and the ass in a single name. Such incongruent, surprising associations are, moreover, typical of orchestral music particularly when a key-change occurs (in traditional Western art music) and in even the minutest of transitions (in case of twentieth century Western art music). In Madam Bello's comment followed by the name Biddy Doran, the perceptive-cum-learned reader will immediately be aware of the deliberate inter-textuality employed by Joyce. To the lay reader, however, the words "ass" and "Doran" in Madame Bello's comment would not be of any special import (except that they would be treated as parts of a swear-phrase) just as the name Biddy Doran would be as good as any other name. In the latter case, Joyce achieves the intended de-contextualization of words in that the words shed their original context and take on that of being parts of a swear-phrase. On the other hand, the learned reader (aware of the existing ballad) will have the anality connection (which, due to its sexual potential, makes an impact) resonating in his mind whenever he listens to subsequent renditions of the ballad. Joyce has, for him, changed the connotations of the ballad for good. This is how the written word becomes a part of multiple significatory grids in a text like Ulysses. This phenomenon of individual signs (words/phrases) branching off intricately and indefinitely to become a cog in numerous significatory networks could be taken to be anticipating the New Media aesthetic of 'hypertext', which is one of the fundamental pillars on which the New Media digital art and technology is hinged.

Music as an art, unlike literature, possesses only semiotic potential (since it does not have the referential/representational component) which is why the status of a single note (which is the smallest unit in music) is arguably devoid of ideological charge. Music communicates via the assemblage of a complex of notes which evokes a certain emotional or sensory register.

Joyce, in exploiting the syllabic, material and acoustic properties of letters/words suspends the written word in a semiotic interplay similar to music, where signification occurs neither through regular phrases/sentences nor through the significatory capacity of the lexical word but through word-complexes(as a parallel to the complex of notes through which music communicates). A few instances from the text of Ulysses are in order.

"Bloom. Flood of warm jamjam lickitup secretness flowed to flow in music out, in desire, dark to lick flow invading. Tipping her tepping her tapping her topping her. Tup. Pores to 
dilate dilating. Tup. The joy the feel warm the. Tup. To pour o'er sluices pouring gushes. Flood, gush, flow, joygush, tupthrob. Now! Language of love... Her wavyavyeavyheavyeavyevyevyhair un comb:'d." (Ulysses, p. 496)

The idiosyncratic stylistics of the preceding passage evince Joyce's impulse to communicate through what I have termed 'word-complexes' where formulations like 'jamjamlickitup' or 'wavyavyeavyheavyeavyevyevy', though comfortably nested within a regular sentence, do not communicate as regular components of the sentence. Though both the word groups fulfill adjectival roles in the sentence, their adjectival nature complies with neither adjectives nor adjectival phrases in the traditional sense of the terms. Instead, they form isolated instants of meaning, as it were, superimposed on the regular syntax of the sentence.

The unpunctuated character of these 'word-complexes', besides expressing fits of abruptly conceived motion, also captures the processual dynamics of signification itself. Such isolated, selfcontained instants like 'lickitup', moreover, occupy a subliminal status in the economy of the text in that they are in a productive tension with multiple networks or grids of signification and often resurface in various guises, forming a 'textual unconscious', as it were. As explicated earlier, music communicates by invoking emotional registers using groups of notes and exists in time. By coining word-complexes like 'lickitup', Joyce, rather than invoking the stable realm of the ethereal signified, is conjuring up the temporal aspect of meaning making where the individual words assume the roles of musical notes, as it were, trying to evoke a fundamental emotional register through their embodied affective potential.

It is important to speculate on how this radical recasting of the written word modifies perceptual dynamics and entails a remarkable re-mapping of the affect experienced by the reader/ (perceiver?). Henri Bergson, in Matter and Memory posits that the external world is a "universal flux of images. The body is itself an image among other images-in fact a very special kind of image Bergson calls a "center of indetermination," which acts as a filter creatively selecting facets of images from the universal flux according to its own capacities. The body, then, is a source of action on the world of images, subtracting among external influences those that are relevant to its own interests. Bergson calls such isolated image components "perceptions."' (as cited in Hansen,2004, p. xix)

The role of the perceiver in selectively processing and 'enframing' images apparently undergoes an interesting modification when he encounters a style of writing like the one in Ulysses. The embodied perceiver does not remain a unidimensional, passive receptor of images/signifieds whose body filters images as per his capacity and relevance (a la Bergson). The semioticity of the written word in Joyce draws the reader/perceiver into a new relation premised on interactivity, participation and communicability with the materiality (visual and acoustic) of the sign/word whereby never-ending strings of unpunctuated and often distorted signifiers demand the active intervention of the reader to create networks of signification.

Consider the following string:

"Nationalgymnasiummuseumsanatoriumandsuspensoriumso rdinaryprivatdocentgeneralhistoryspecialprofessordoctor Kriegfried Ueberallgemein”(Ulysses p.558)

It challenges the reader with the intimidating task of visually and semantically punctuating the text on the one hand and sensorily experiencing the text on the other. The aesthetic of interactivity inaugurated by this radical mode of writing anticipates the processual and dynamic aspects of the New Media digital art of modern times. This transition of the status of the consumer/reader from a detached interpreter to an involved participant marks a signal moment, I 
hold, in art historical discourse, given that the entirety of Media Art discourse is predicated on an aesthetic of interactivity and participation where the consumer enters into a direct collaboration with the artist as, in some senses, a producer of the artwork.

Joyce further experiments with auditory resources in Ulysses when he uses strings like 'Diddleiddle addleaddle ooddleooddle' or 'wavyavyeavyheavyeavyevyevy'. These sounds because of their prolonged vowels approach musical sound but retain their status as un-musical components of speech-sounds. The hybrid status of such strings which lie on the borderland of speech and music attain their identity through a dialectical negation- by masquerading as neither- music-nor-speech. Like modulated bird voices, these hybrid registers manage to dismantle the music/non-music binary and expose the intermediary, subliminal possibilities of sound.

Joyce engages with the materiality of the written signifier by making a detour around acoustic materiality. Interestingly, the literary medium or the written text, in popular imagination, is almost always conceived as devoid of a material source/origin. This is unlike the prevalent conception of music/sound which (owing to the variety of sources/instruments which can produce it) is always associated with a unique source of production. Human intuition struggles to locate the source of a sound the moment it encounters it. With the written text, however, there is no such concomitant urge since words/syllables (in a particular language) can be chosen only from the range of alphabets available, which is limited and immediately recognisable. Thus, I note that, in order to foreground the materiality of the signifier, Joyce is singularly obsessed with sound not only as abstract sensory information but also as emitted by an organic, material source. The following passage from the Sirens episode in Ulysses might be considered:

"Chamber music. Could make a kind of pun on that. It is a kind of music I often thought when she. Acoustics that is. Tinkling. Empty vessels make most noise. Because the acoustics, the resonance changes according as the weight of the water is equal to the law of falling water. Like those rhapsodies of Liszt's, Hungarian, gipsyeyed. Pearls. Drops. Rain. Diddleiddle addleaddle ooddleooddle"(Ulysses, p. 511-12)

In such passages, Joyce vacillates between music as a superstructural art-form on the one hand and music as sonic experience on the other, associated with non-musical sources of production. The obsession with the source of sonic experience is aimed at indirectly invoking the materiality associated with any sonic experience. Sound does not emanate out of the blue but is associated with material phenomena which could be controlled and manipulated, just as literary meaning could be manipulated by playing with the material sign (the word/letter(s)). It is to unravel the role of media (print/audio) in the production of information/knowledge and to thus expose the constructed nature of knowledge that Joyce is concerned with the materiality of the sign.

The constant interplay between what Theodore Adorno calls "material form"(where the form superimposes itself on and hence frames the musical material) and "academic form" (where the musical material produces the formal category), is of unmatched significance, in my view, in the political, economic and aesthetic horizons of Joyce's 'melopoetics'. Joyce, in Ulysses, is preoccupied with staging a tension between generic/academic forms on the one hand and employing the musical material (unfiltered through any superimposed generic code) to generate the form, as it were. The academic/generic forms are more often than not thrown into relief by means of excessive stylization and skepticism which constantly foreground their status as constructed artifice enmeshed in "ideological closure". An entire line of commentators has tried 
to read Ulysses through the lens of musical forms and genres like the fugue or the sonata with Joyce himself proclaiming that the Sirens episode was modelled on the fuga per canonem (a certain musical form). The critical bid to excavate musical genres out of Ulysses exists in tension with the contrary impulse of foregrounding generic codes as infected with and framed within political, linguistic and ideological constraints. It is a critical commonplace that generic forms are inevitably marked by ideology and value. For instance, the Romantic idea of music as an ideal, transcendental and self-enclosed realm, which is in stark contrast with the modernist and postmodernist association of music with acoustics, "modulated sonic patterning" and industrial noise, readily comes to mind. Much of the textual space of Ulysses stages this tension and attempts to enter a realm devoid of generic and cultural codes and ideology.

\section{Beckett-ian Aesthetics and the Phenomenology of the Material}

"All known all white bare white body fixed one yard legs joined like sewn. Light heat white floor one square yard never seen... Bare white body fixed only the eyes only just. Traces blurs light grey almost white on white. Hands hanging palms front white feet heels together right angle. Light heat white planes shining white bare white body fixed ping fixed elsewhere."(Ping)

Samuel Beckett's experimental short story Ping has had much critical ink spent on it, trying to decipher its central theme, the identity of the narrator, its genre and its central import. I, however, plot the intellectual co-ordinates of the text along alternative philosophical and aesthetic terrains. I begin by elaborating on the manifest impingement of the auditory and critical resources of post-modernist musical works on the text.

The text earmarks a fundamental matrix of words/phrases/expressions which, in the course of the text undergoes a staggering range of internal permutation, combination and repetition. This overtly resembles the artistic techniques of serialist music (exemplified by the likes of John Cage, Karlheinz Stockhausen and Pierre Boulez). Serialist music, like the text under consideration, lays out a comprehensive set of musical elements intended to be a part of the 'musical' experience. In the course of the musical text, the various permutational and combinatory possibilities are explored and articulated. Rather than exploring the evocative potential of musical notes to conjure up static emotions, serialist music is a processual form of music where musical/sonic signification is provisional, tentative, processual and contingent. It is predicated on the logic of freeplay of musical material. This ethos significantly informs Beckett's style in Ping where he all but dismisses considerations of standard syntax and sentence formation in English and embarks on an odyssey of formal and semantic exploration.

On reading the story-text, it seems as if the multiple permutational variations that the fundamental set of words/phrases in the text are subjected to, have been electronically or mechanically generated. This, seemingly, is premised on the logic of random permutation. Pierre Boulez, in his classic work Orientations, comments, "[G]rammatical associative logic makes it difficult for words to be interchanged without a phrase losing part of all of its meaning.... In music, on the other hand, the logic of construction is less rigorously limited in validity: the nonsignificance and non-direction of the musical object in its primitive state make it usable in structured organisms, in accordance with formal principles much" (Boulez, 1985 ,p.148) In its stupefying panoply of sensory stimulus, the world of Ping is one of irredeemably disorienting and dystopic possibilities where, apart from the 'metronomic' ping which punctuates the text, the reader is abandoned without an anchor. The written word no longer remains a transmitter (to use an anachronistic term) of representational meaning but is recast to apprehend the immediacy of 'perceptual reality'. 
However, this paper is interested in exploring the aesthetics of the text in a different light.

Instead of speculating on the semantic features of the text like the questions of narration, meaning, memory, consciousness and so on, it is in the interest of this paper to look at how Ping gesturally stages a dialectic between superstructural/metaphysical concerns like consciousness, time, identity and the sensory ecology that not only modifies, but even shapes these metaphysical themes with regard to the perceptual and cognitive dynamics of both the reader and the textual non-subject whose bodily organs are broached synecdochically within the textual space.

Adopting a metadiscursive stance, as it were, Beckett thematizes metaphysical constructs like time, memory and identity by projecting them as effects of language. This classic move is in line with poststructuralist ideology where the notions of 'self, 'center' and 'subject' undergo drastic revision. The autonomy and agency of such metaphysical constructs are dismantled with an uncanny ease when what I would call the human(symbolized by a generous smattering of words like 'consciousness', 'time', 'memory') steps into a confrontational space with the material(the inanimate environment of the white room in which the non-subject is placed).

For instance, in the apathetic world of Ping, the presence of the imploring eye with lashes half closed' has grabbed the attention of many commentators who have then regarded this rare instance of life to be the last trace of the human in this ruthless linguistic and sensory universe of raw matter. However, if one considers the syntactic position of the phrase containing the instance of the 'imploring eye', it is difficult to give unqualified assent to such contentions. The sentence is as follows, "Ping elsewhere always there but that known not. Ping perhaps not alone one second with image same time a little less dim eye black and white half closed among lashes imploring that much memory almost never."(Beckett) If the semantic charge of an image is seldom gleaned in isolation, one has to consider the isolated image of the 'imploring eye' in conjunction with its textual environment. In other words, the lifeless and grotesque environment within which the evocative lone image of the 'imploring eye' is embedded serves to foreground its status as hardly anything other than an inanimate perceptual organ, thus rendering it devoid of its otherwise human element. The emotional content of the image of the "imploring eye" only serves to draw attention to itself as a textual element which defamiliarizes the raw, sensory universe of Ping, exposing its status as rhetorical artifice in the process. In a similar fashion, metaphysical concepts associated with qualitative worth like time, consciousness and identity are treated as linguistic objects, as it were, thereby inaugurating a new 'phenomenology of pure perception'. It is interesting to note how this aesthetic strategy straddles the various dimensions of an intellectual debate regarding musical hermeneutics that has hit the intellectual circles over the past two decades. An elucidation is in order, to understand the politics of Beckett's aesthetics in Ping.

A significant contribution to the field of musical hermeneutics was an appropriation of James Gibson's(1979) ${ }^{3}$ ecological perceptual theory to reconfigure the idea of meaning in music. ${ }^{1}$ The traditional cognitivist school contends that meaning resides in the formal, tonal and metrical content of a musical composition. In contrast, the conceptual thrust of Gibson's theory is premised upon the perceiving organism's capacity to cognize through events and objects specified in the environment. According to Gibson, organisms actively participate in looking for perceptual objects in their sensory environment. The approach espoused by the standard cognitive sciences is that the organism is a passive recipient of sensory stimuli in a temporal succession which in turn triggers cognitive processes. Gibson overturns this idea by claiming that the sensory level succeeds instead of preceding the cognition of the object in the environment. In other words, we do not perceive at the level of sense stimuli or sense perception but at the level of entire objects 
and events. This perception is active and engenders action. The interior cognitive processes are exteriorized and it singularly foregrounds the materiality and objective/public nature of interpretation. By relocating the source of perception in extra 'musical' factors like acoustics, the circulatory media, the sonic properties of the source, the timbre of the musical instrument and so on, the cognitive autonomy of the listening subject is reduced to a mechanical determinism, a public, objective realm, as it were. The cognitive scientists conceptualize perception as passive and occurring temporally through a series of sensory stimuli while Gibson proposes perception in terms of spatially adjacent objects and events specified in the individual's environment.

Beckett, in my understanding, anticipates the crux of this nuanced aesthetic debate in Ping, though under widely different circumstances. Metaphysical concepts like 'consciousness', and the 'self', which masquerade as autonomous, abstract entities, assume this status only when they are perceived through cultural and generic codes within a realm of pre-assigned values. In Ping, however, they are suspended within an environment almost devoid of cultural values and generic codes. The clinical precision that goes into describing each of the elements (spatial, temporal or objective) that the text introduces, turns it into a phantasmagoric entity, animated with an embodied materiality, as it were. Since the space of the text is almost devoid of any cultural or generic filters, the described objects (including concepts like 'time', 'consciousness' and 'memory') hit the reader/perceiver as raw objective reality instead of a constructed epistemology. Entities like 'consciousness' and 'memory', in the descriptive economy of the text are in dialogue with and are thus being constantly shaped by the textual environment comprising crude perceptual objects in space and time. The text, in effect obliterates the conceptual/material, interior/exterior or, for that matter, the public/public binaries through what seems to be a radical recasting of the written word across registers of raw perception and objective materiality.

Generic classification of Beckett's style as stream of consciousness is problematic in that the ritual acoustic disruption in the form of the auditory ping (which anchors the otherwise rambling, ethereal stream of the narratorial mindscape) makes the material/abstract distinction problematic since the abstract string of mental images is always already infected with the material/acoustic ping as part of its constitutive apparatus, as it were. I read this as a metadiscursive comment on how all such illusions of abstract, conceptual knowledge(the hermetic stream of consciousness in this case) are kept up, paradoxically, by media technology to cover over its own epistemological and ontological politics.

Further, the existence of the elements (ocular/auditory/haptic) in the text as phenomenological, isolated events, inaugurates an aesthetic of radical interactivity and communication (unfiltered through conceptual and generic codes) which, in many ways, anticipates the temporal and spatial rootedness of New Media aesthetics. The 'perceptual ecology'of an organism, to use a Gibsonian term, is crucial in determining patterns of interaction and interrelations with, and interpretation of the synaesthetic environment of New Media art. Ping, in my reading, opens up such an interactive dynamic by constituting the perceptual ecology of the non-subject by employing clinically precise description.

\section{Notes}

1. For a detailed discussion, refer to Lakoff G., Johnson M. (1980): Metaphors We Live By, Chicago: University of Chicago Press

2. For a detailed account, refer to the chapter A Material Theory of Form in Paddison, Max. 1993. Adorno's Aesthetics of Music. Cambridge: Cambridge University Press. 
3. A detailed discussion of Gibson's theory and its ramifications is to be found in the first chapter titled Perception, Ecology and Music of Eric F Clarke's (2004) book Ways of Listening: An Ecological Approach to the Perception of Musical Meaning. Oxford: Oxford University Press

\section{References}

Beckett, Samuel (2016, December 15). Ping. Retrieved from http://www.samuel-beckett.net/ping.html

Boulez, Pierre. (1985). Orientations: Collected Writings. Jean-Jaques Nattiez(Ed.). Martin Cooper(Trans.). Cambridge: Harvard UP.

Danius, Sara. (2002). The Senses of Modernism: Technology, Perception, and Aesthetics. Ithaca: Cornel University Press.

Hansen, Mark.(2004). New Philosophy for New Media. Cambridge, Massachusetts: The MIT Press.

Joyce, James.(1922). Ulysses. 'Planet PDF. Retrieved from

<http://www.planetpdf.com/planetpdf/pdfs/free_ebooks/Ulysses_NT.pdf>

Kumar, Udaya.(1991). The Joycean Labyrinth: Repetition, Time and Tradition in “Ulysses”. Oxford: Clarendon Press.

Nestrovski, Arthur. (1994). Joyce's Critique of Music. Perspectives on Musical Aesthetics. John Rahn(Ed.). New York:Norton.

Ronit Ghosh is a graduate student at the Department of Art and Technology, Aalborg University, Denmark. Interested in the philosophy of aesthetics in general, he has presented his research at numerous (inter)national conferences and has publications on sound studies forthcoming in the International Journal on Stereo and Immersive Media and Journal of Sonic Studies. ORCID ID is oooo-0002-8668-1286. 